\title{
Graves disease in infancy: a patient presentation and literature review
}

\section{Kara Alex-Ann Beliard1', Srinidhi Shyamkumar², Preneet Cheema Brar ${ }^{3}$ and Robert Rapaport ${ }^{1}$}

IIcahn School of Medicine, Mount Sinai Department of Pediatric Endocrinology, Kravis Children's Hospital, New York, NY, USA, ${ }^{2}$ Touro College of Osteopathic Medicine, New York, NY, USA, and ${ }^{3}$ Division of Pediatric Endocrinology, New York University Grossman School of Medicine, New York, NY, USA
Correspondence should be addressed to K A-A Beliard

Email

beliardkara@gmail.com

\section{Summary}

We describe a case of an infant who presented with clinical features of hyperthyroidism. The child was found to be tachycardic, hypertensive and diaphoretic, she was noted to have poor weight gain and difficulty in sleeping. The child was admitted to the pediatric intensive care unit for care. She was found to have biochemical evidence of hyperthyroidism with positive thyroid stimulating immunoglobulin. She responded well to methimazole and propranolol and had a remarkable recovery. She is the youngest patient to be diagnosed with Graves disease in the English literature, at 12 months of life.

\section{Learning points:}

- Hyperthyroidism must always be considered even at very young age, for patient presenting with poor weight gain and hyperdynamic state.

- Autoimmune diseases are becoming more common in infancy.

- Craniosynostosis and increased height for age are well-documented consequences of untreated hyperthyroidism in developing children.

\section{Background}

Graves disease (GD) is the most common cause of hyperthyroidism worldwide. The annual incidence of childhood hyperthyroidism is estimated to be 1 per $1,000,000$ in children younger than 4 years of age without female predominance (1). The usual age of presentation is between 20 and 30 years, and it is more common in females. Different causes of hyperthyroidism include Graves Disease (GD), exogenous hormone consumption, and toxic adenoma, with the former being the most common at all ages. The neonatal form of GD is seen in approximately $0.6 \%$ of children born to mothers with active or inactive GD (2). The maternal thyroidstimulating hormone receptor antibodies (TRAb) traverse the placenta and stimulate the newborn's thyroid gland leading to a transient hyperthyroid state. The disease self- resolves, generally by 6 months of life, as the infant clears the maternal antibodies $(2,3,4,5,6,7,8)$. It is, however, extremely infrequent in infants. Only four cases of Graves disease in children under the age of 2 have been reported in the literature. Although rare, the complications can be devastating, so identifying and treating GD in infants are vital. Along with reviewing the literature on Graves disease in infancy, we describe an infant who presented at 12 months of life with intermittent facial flushing and poor weight gain.

\section{Case presentation}

A 12-month-old female presented to her pediatrician with poor weight gain, occasional facial flushing, and nighttime 
restlessness. The child was born at term, adequate for gestational age with a birth weight of $3.22 \mathrm{~kg}(-0.37$ S.D.), birth length of $51 \mathrm{~cm}(0.67$ S.D.), and head circumference of $33.5 \mathrm{~cm}$ ( -0.78 s.D.), following an uncomplicated pregnancy to two healthy Asian parents. The mother was clinically euthyroid during pregnancy, had no exposure to iodine-containing products and no family history of thyroid-related illness or auto-immune conditions were reported.

\section{Investigation}

The child was found to have an undetectable thyroid stimulating hormone (TSH) level and a free $\mathrm{T} 4 \mathrm{of} 2.1 \mathrm{ng} / \mathrm{dL}$ (normal $0.80-1.50 \mathrm{ng} / \mathrm{dL}$ ). She was referred to a pediatric endocrinologist where she was noted to be tachycardic at a heart rate of $149 \mathrm{bpm}$, with significant perspiration on the scalp as well as her palmar and plantar surfaces and had a slightly palpable thyroid gland, but no tremors, irritability, lid lag or stare. She was admitted to the pediatric intensive care unit (PICU) due to concerns of thyroid storm. In the PICU, she was noted to have a blood pressure of 141/104 $\mathrm{mmHg}$ and pulse of $220 \mathrm{bpm}$ with sinus rhythm on ECG.

\section{Treatment}

She was started on propranolol $2 \mathrm{mg} \quad \mathrm{Q} \quad 8 \mathrm{~h}$ $(0.78 \mathrm{mg} / \mathrm{kg} / \mathrm{day})$ and methimazole $1.25 \mathrm{mg}$ BID $(0.3 \mathrm{mg} / \mathrm{kg} /$ day $)$. Results from her thyroid ultrasound revealed an unremarkable gland.

\section{Outcome and follow-up}

She had positive thyroid peroxidase antibodies (TPO) of $21.60 \mathrm{IU} / \mathrm{mL}$ (normal $0.00-5.60 \mathrm{IU} / \mathrm{mL}$ ), Thyroglobulin antibodies (TgAb) of $0.90 \mathrm{IU} / \mathrm{mL}$ (normal $0.00-4.10$ $\mathrm{IU} / \mathrm{mL}$ ), and thyroid stimulating immunoglobulin (TSI) level of $263 \mathrm{IU} / \mathrm{L}$ (normal 0.00-0.55IU/L), confirming the diagnosis of GD. She was discharged home 2 days later, on methimazole and propranolol.
She continues to be followed in our Pediatric Endocrinology clinic. At her 24 months visit, she remains on methimazole due to persistently high TSI. She is currently clinically euthyroid (Table 1 ). Her most recent measurements recorded for length of $83.8 \mathrm{~cm}(-0.74$ s.D.), with a weight of $9.2 \mathrm{~kg}(-2.77$ S.D.) and head circumference of $45.7 \mathrm{~cm}(-1.38$ s.D.), as compared to her measurements at the time of diagnosis; the weight of $7.8 \mathrm{~kg}$ ( -2.3 S.D.), length of $72.4 \mathrm{~cm}(-0.98$ S.D.) and head circumference of 44 $\mathrm{cm}(-1.12$ S.D.). She has attained all of her developmental milestones appropriately.

\section{Discussion}

Autoimmune thyroid disease is the most common cause of acquired thyroid illness worldwide in all age groups. Patients can present with either Graves disease or Hashimoto's thyroiditis (HT), which are both T-cell mediated inflammatory dysfunctions of the thyroid gland. The cause of thyroid autoimmunity is not well understood but seems to be multifactorial. Various genes and proteins have been associated with the development of autoimmune thyroid disease, including but not limited to HLA-DR, PTPN22 and CD40 (9). The disease incidence increases with age, with adolescence being the most common age of presentation in the pediatric population (10). Autoimmune thyroid disease is rarely seen in children less than 3 years old, but some cases have been reported; Østergaard et al. described a 7-month-old child presenting with myxedema coma in the setting of HT (11). In regards to Graves disease, to our knowledge, only four patients between the ages of 0 and 24 months have been described in the English literature. They were all believed to have had symptoms at a younger age but were diagnosed and treated many months later (Table 2). This significant delay in diagnosis and treatment may be due to the overall rarity in this age group and the insidious onset of hyperthyroidism, commonly presenting as goiter, tachycardia, restlessness, and exophthalmos, some with failure to thrive and gastrointestinal manifestations.

Table 1 Laboratory values over time.

\begin{tabular}{l}
\hline Age (months) \\
\hline Free T4 $(n=0.85-1.75 \mathrm{ng} / \mathrm{dL})$ \\
TSH $(n=0.70-5.97 \mathrm{ulU} / \mathrm{mL})$ \\
Thyroid stimulating immunoglobulin $(\mathrm{TSI})(n=0.00-0.55 \mathrm{IU} / \mathrm{L})$ \\
Thyroglobulin antibody $(n=0-5 \mathrm{IU} / \mathrm{mL})$ \\
Thyroid peroxidase antibodies (TPO) $(n=0-5.5 \mathrm{IU} / \mathrm{mL})$ \\
\hline
\end{tabular}

\begin{tabular}{|c|c|}
\hline 12 & 13 \\
\hline \multirow{5}{*}{$<0.01$} & 2.1 \\
\hline & $<0.02$ \\
\hline & 263 \\
\hline & 0.9 \\
\hline & 21.6 \\
\hline
\end{tabular}

\begin{tabular}{c}
\hline $\mathbf{1 6}$ \\
\hline 1.4 \\
$<0.02$ \\
329 \\
\end{tabular}

\begin{tabular}{c}
\hline $\mathbf{1 8}$ \\
\hline 1.23 \\
8.5 \\
58.3 \\
\end{tabular}

\begin{tabular}{|c|c|}
\hline 21 & 24 \\
\hline 1.48 & 1.69 \\
\hline 0.129 & 0.028 \\
\hline 66.1 & 67.6 \\
\hline
\end{tabular}




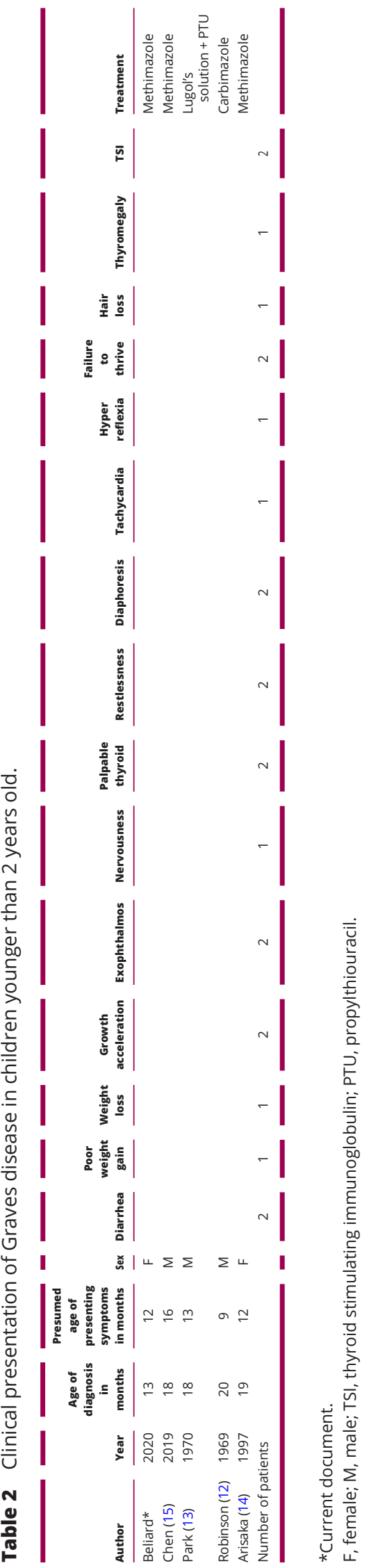

Robinson et al. diagnosed a 20-month-old child with GD when he presented with poor weight gain since 9 months of age, chronic diarrhea, and restlessness since the age of 15 months. At that time, a goiter with a loud bruit, tachycardia, hypertension, as well as a stare without exophthalmos was detected (12). Park et al. diagnosed an 18-month-old child who presented with failure to thrive, hair loss, stare, restlessness, thyromegaly, tachycardia, and hypertension. The patient had been experiencing tachycardia, frontal bossing, and advanced bone age since the age of 13 months (13). Arisaka et al. diagnosed a 19-month-old girl with GD when she was found to have exophthalmos, restlessness, diaphoresis, goiter, and tachycardia with linear growth acceleration. She otherwise had a normal development. Some of her symptoms were recounted to have started around her first birthday (14). More recently, Chen et al. described a child who was diagnosed with GD at 18 months of age with mild exophthalmos and a palpable thyroid gland. He initially presented at 16 months with chronic diarrhea and emesis, leading to weight loss (15). Craniosynostosis and increased height for age are well-documented consequences of untreated hyperthyroidism in developing children. Nonetheless, they were not noted in any of these cases or our patient.

We present an infant, who was found to have an undetectable TSH and elevated free T4 at 12 months of life, associated with poor weight gain and restlessness. She was also found to be diaphoretic, with tachycardia and hypertension. She had moderately positive TPO antibodies and markedly elevated TSI. Her thyroid gland was palpable, although no thyromegaly was reported on imaging. The child responded well to propranolol and methimazole. In contrast to the cases of a similar age group previously mentioned, she did not have any gastrointestinal symptoms nor was she found to have any ocular changes. The consistent finding in all children reported above is a palpable thyroid gland. Three out of four of the reviewed cases were found to have either weight loss or failure to gain weight, hypertension, or tachycardia, as well as restlessness.

The first-line therapy for GD in children less than 5 years old is methimazole (16). Propylthiouracil (PTU) is not commonly used as a first-line agent due to its black box warning of liver damage. Since GD can eventually go into remission, medical treatment is attempted as the first-line method. Radioactive iodine and surgical removal of the gland are considered second-line treatment methods.

The development of autoimmune thyroid disease at a young age may be caused by an environmental insult in a child who is genetically predisposed. Some studies 
have shown a seasonality to the presentation of the GD with the theory of molecular mimicry, which happens when the human body produces self-antigens in response to a viral or bacterial exposure, raising the question of infectious triggers to the disease (2). Several reports have found an increasing prevalence of autoimmune disease in the pediatric population over the past decades, especially in type I diabetes mellitus $(17,18)$. The possibility of concomitant other autoimmune disorders must always be considered, as some studies have reported a significant association between autoimmune thyroid disease, GD and HT, with other autoimmune illnesses; notably, type 1 diabetes mellitus and celiac disease (19). For this reason, periodic screening for different autoimmune diseases is important in this patient population. Some studies have suggested that genetically predisposed children who are exposed to cow's milk protein in formula early in life are at higher risk for autoimmune diseases $(20,21)$. However, the TRIGR (Trial to Reduce Insulin Dependent Diabetes Mellitus in the Genetically at Risk) study, which was a large and multinational clinical trial, demonstrated no significant increase in type I diabetes mellitus incidence in genetically predisposed children who were weaned to a hydrolyzed formula compared to conventional formula (22). Children with chromosomal disorders like Turner syndrome and Down syndrome are known to have an increased risk of associated autoimmune thyroid disease. HT can be preceded by GD, and less commonly the conversion from HT to GD has been observed (23). This conversion is theorized to be due to a switch in the biological activity of TRAb and its ability to have blocking and stimulating effects on the thyroid gland, although this statement has not been proven $(23,24,25)$.

\section{Conclusion}

This report describes the youngest child to be diagnosed with GD in the published English literature. Our patient shares most of the signs and symptoms of other children in her age group who have been previously described. The reason for which this disease develops at such a young age remains unclear, but a very high TSI may implicate an early onset of autoimmunity. To enhance knowledge about GD in infancy, we propose maintaining a registry of cases with genetic studies, monitoring the disease and time course of TSI persistence, and correlating with a duration of illness. This may help predict the likelihood of disease remission, as opposed to undergoing definitive but invasive treatments such as radioactive iodine and surgery. Pediatricians must have a high index of suspicion to diagnose and treat infants with GD promptly.

\section{Declaration of interest}

The authors declare that there is no conflict of interest that could be perceived as prejudicing the impartiality of the research reported.

\section{Funding}

This research did not receive any specific grant from any funding agency in the public, commercial or not-for-profit sector.

\section{Patient consent}

The parents have provided informed consent for publication of the submitted article.

\section{Author contribution statement}

Dr Beliard and Ms Shyamkumar designed the case report, collected data, drafted the initial manuscript and revised the manuscript; Dr Rapaport and Dr Brar conceptualized and revised the manuscript; and all authors approved the final manuscript as submitted and agree to be accountable for all aspects of the work.

\section{References}

1 Lavard L, Ranløv I, Perrild H, Andersen O \& Jacobsen BB. Incidence of juvenile thyrotoxicosis in Denmark, 1982-1988. A nationwide study. European Journal of Endocrinology 1994130 565-568. (https://doi. org/10.1530/eje.0.1300565)

2 Cappa M, Bizzarri C \& Crea F. Autoimmune thyroid diseases in children. Journal of Thyroid Research 20102011 675703. (https://doi. org/10.4061/2011/675703)

3 Ramsay I, Kaur S \& Krassas G. Thyrotoxicosis in pregnancy: results of treatment by antithyroid drugs combined with T4. Clinical Endocrinology 198318 73-85. (https://doi. org/10.1111/j.1365-2265.1983.tb03188.x)

4 Mckenzie JM \& Zakarija M. Fetal and neonatal hyperthyroidism and hypothyroidism due to maternal TSH receptor antibodies. Thyroid 19922 155-159. (https://doi.org/10.1089/thy.1992.2.155)

5 De Groot L, Abalovich M, Alexander EK, Amino N, Barbour L, Cobin RH, Eastman CJ, Lazarus JH, Luton D, Mandel SJ, et al. Management of thyroid dysfunction during pregnancy and postpartum: an Endocrine Society clinical practice guideline. Journal of Clinical Endocrinology and Metabolism 201297 2543-2565. (https://doi. org/10.1210/jc.2011-2803)

6 Yoshihara A, Iwaku K, Noh JY, Watanabe N, Kunii Y, Ohye H, Suzuki M, Matsumoto M, Suzuki N, Tadokoro R, et al. Incidence of neonatal hyperthyroidism among newborns of Graves disease patients treated with radioiodine therapy. Thyroid 201929 128-134. (https://doi. org/10.1089/thy.2018.0165)

7 Van Der Kaay DCM, Wasserman JD \& Palmert MR. Management of neonates born to mothers with Graves disease. Pediatrics 2016137 e20151878. (https://doi.org/10.1542/peds.2015-1878)

8 Skuza KA, Sills IN, Stene M \& Rapaport R. Prediction of neonatal hyperthyroidism in infants born to mothers with Graves disease. Journal of Pediatrics 1996128 264-268. (https://doi.org/10.1016/s00223476(96)70405-5) 
9 Jacobson EM \& Tomer Y. The genetic basis of thyroid autoimmunity. Thyroid 200717 949-961. (https://doi.org/10.1089/thy.2007.0153)

10 Rydzewska M, Jaromin M, Pasierowska IE, Stożek K \& Bossowski A. Role of the $\mathrm{T}$ and $\mathrm{B}$ lymphocytes in pathogenesis of autoimmune thyroid diseases. Thyroid Research 201811 2. (https://doi.org/10.1186/s13044018-0046-9)

11 Ostergaard GZ \& Jacobsen BB. Atrophic, autoimmune thyroiditis in infancy. A case report. Hormone Research 198931 190-192. (https://doi. org $/ 10.1159 / 000181114$ )

12 Robinson DC, Hall R \& Munro DS. Graves disease, an unusual complication: raised intracranial pressure due to premature fusion of skull sutures. Archives of Disease in Childhood 196944 252-257. (https:// doi.org/10.1136/adc.44.234.252)

13 Park RW \& Frasier SD. Hyperthyroidism under 2 years of age. American Journal of Diseases of Children 1970120 157-159. (https://doi. org/10.1001/archpedi.1970.02100070101015)

14 Arisaka O, Hosaka A, Arai H, Fujiwara S, Tadokoro R \& Yabuta K. Graves disease associated with exophthalmos, cerebral ventricular dilatation and accelerated growth. Archives of Disease in Childhood 199776 62-64. (https://doi.org/10.1136/adc.76.1.62)

15 Chen J, Eng L \& Lam L. MON-263 Graves' disease presenting as chronic diarrhea in a toddler. Journal of the Endocrine Society 20193 MON-263. (https://doi.org/10.1210/js.2019-MON-263)

16 Rivkees SA. Pediatric Graves' disease: management in the postpropylthiouracil Era. International Journal of Pediatric Endocrinology 20142014 10. (https://doi.org/10.1186/1687-9856-2014-10)

17 Gyurus EK, Patterson C, Soltesz G \& Hungarian Childhood Diabetes Epidemiology Group. Twenty-one years of prospective incidence of childhood type 1 diabetes in Hungary - the rising trend continues (or peaks and highlands?). Pediatric Diabetes 201213 21-25. (https://doi. org/10.1111/j.1399-5448.2011.00826.x)

18 Podolakova K, Barak L, Jancova E, Stanik J \& Podracka L. Increasing incidence of type 1 diabetes mellitus in young children in Slovakia.
Bratislavske Lekarske Listy 2020121 129-132. (https://doi.org/10.4149/ BLL 2020_017)

19 Patelarou E, Girvalaki C, Brokalaki H, Patelarou A, Androulaki Z \& Vardavas C. Current evidence on the associations of breastfeeding, infant formula, and cows milk introduction with type 1 diabetes mellitus: a systematic review. Nutrition Reviews 201270 509-519. (https://doi.org/10.1111/j.1753-4887.2012.00513.x)

20 Koivusaari K, Syrjälä E, Niinistö S, Takkinen HM, Ahonen S, Åkerlund M, Korhonen TE, Toppari J, Ilonen J, Peltonen J, et al. Consumption of differently processed milk products in infancy and early childhood and the risk of islet autoimmunity. British Journal of Nutrition 2020124 1-8. (https://doi.org/10.1017/S0007114520000744)

21 Writing Group for the TRIGR Study Group, Knip M, Åkerblom HK, Al Taji E, Becker D, Bruining J, Castano L, Danne T, de Beaufort C, Dosch HM, et al. Effect of hydrolyzed infant formula vs conventional formula on risk of type 1 diabetes: the TRIGR Randomized Clinical Trial. JAMA 2018319 38-48. (https://doi.org/10.1001/jama.2017.19826)

22 Aversa T, Corica D, Zirilli G, Pajno GB, Salzano G, De Luca F \& Wasniewska M. Phenotypic expression of autoimmunity in children with autoimmune thyroid disorders. Frontiers in Endocrinology 201910 476. (https://doi.org/10.3389/fendo.2019.00476)

23 Aversa T, Lombardo F, Corrias A, Salerno M, De Luca F \& Wasniewska M. In young patients with turner or down syndrome, Graves' disease presentation is often preceded by Hashimoto's thyroiditis. Thyroid 201424 744-747. (https://doi.org/10.1089/ thy.2013.0452)

24 Wasniewska M, Corrias A, Arrigo T, Lombardo F, Salerno M, Mussa A, Vigone MC \& De Luca F. Frequency of Hashimoto's thyroiditis antecedents in the history of children and adolescents with Graves' disease. Hormone Research in Paediatrics 201073 473-476. (https://doi. org/10.1159/000313395)

25 Ludgate $\mathrm{M} \&$ Emerson $\mathrm{CH}$. Metamorphic thyroid autoimmunity. Thyroid 200818 1035-1037. (https://doi.org/10.1089/thy.2008.1551)

Received in final form 28 March 2021

Accepted 24 May 2021 